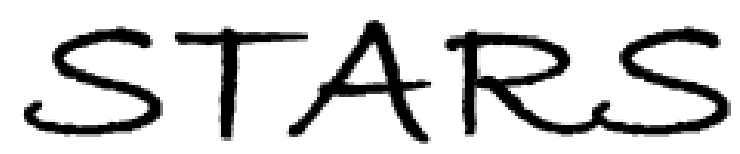

University of Central Florida

STARS

2-19-2015

\title{
The Influence of Others on the Vacation Experience: An Ethnographic Study of Psychographics, Decision Making, and Group Dynamics Among Young Travelers
}

\section{Edwin Torres}

University of Central Florida, edwin.torres@ucf.edu

Part of the Hospitality Administration and Management Commons, and the Tourism and Travel Commons

Find similar works at: https://stars.library.ucf.edu/rosenscholar University of Central Florida Libraries http://library.ucf.edu

This Paper is brought to you for free and open access by the Rosen College of Hospitality Management at STARS. It has been accepted for inclusion in Rosen Faculty Scholarship and Creative Works by an authorized administrator of STARS. For more information, please contact STARS@ucf.edu.

\section{Original Citation}

Torres, E. (2015). The influence of others on the vacation experience: An ethnographic study of psychographics, decision-making, and group dynamics among young travelers. Journal of Hospitality Marketing and Management, 24(8), 826-856.

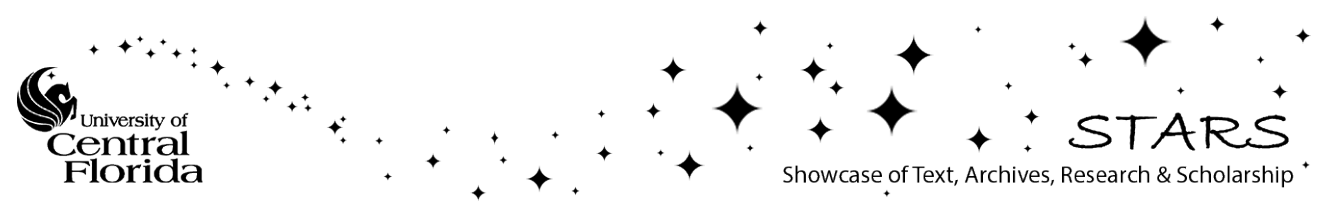




\begin{abstract}
The vacation experience is often enjoyed in the company of others. Whereas scholars have focused on the consumer behaviors of mature travelers, young travelers have received less attention. The present study explores customer-to-customer interactions among young travelers (in their 20s and 30s) within a European tour-group setting. Furthermore, it attempts to understand the influence such travelers have on one another. The decision-making patterns, role of the tour guide, group dynamics, and psychographic preferences are studied from an ethnographic approach. Results indicate that the young travel segment is not as homogeneous as previously conceived. Notable differences in activities, interests, and opinions (AIO) were observed. Additionally, several cases of en-route group purchase decisions were observed. This paper draws upon the concept of compatibility management to advocate for a more targeted approach in appealing to this particular market segment. Conclusions are made regarding the differences among trip participants and potential segmentation strategies are proposed.
\end{abstract}

Keywords: Market segmentation, young travelers, decision making, group dynamics, alcohol consumption, co-production 


\section{The Influence of Others on the Vacation Experience: An Ethnographic Study of Psychographics, Decision Making, and Group Dynamics Among Young Travelers}

The travel experience can be influenced by a variety of factors. Hospitality industry practitioners and academicians often focus on the internal business factors that can affect the enjoyment of a product or service. While internal business factors can be of great consequence to customer satisfaction, or even customer delight, the travel experience is often enjoyed in the presence of other travelers. Therefore, research that considers customer-to-customer influences can be advantageous for both scholars and managers. Consider the average customer who purchases a vacation tour package. After saving for several months or years, analyzing all the options, purchasing a specific package, and setting time away for a vacation, the customers go on their scheduled tour. No matter how good the savings or the research, their experiences, inevitably, will be enhanced or diminished by the other travelers who join the journey. Pleasant travelers with similar desires could enhance a tour, whereas obnoxious guests with different interests can easily ruin a well-planned vacation. Consequently, research that illuminates customer-to-customer interactions in terms of their impact on the enjoyment of hospitality services can be beneficial to both scholars and practitioners. At the present time, a small stream of research illuminates the understanding of such interactions (Huang \& Hsu, 2010; Wikström, 1996; Wu, 2007). However, more research is necessary to gain a better understanding of customer-to-customer dynamics within a tour group.

Prior to participating in a travel experience, customers make various decisions that will ultimately shape their vacation. While much attention has been given to the process of purchasing travel, less emphasis has been placed on the decisions made during the actual trip. 
Decrop and Snelders (2005) suggest that the decision-making process is ongoing. Therefore, it is pertinent to study the decisions that are made during the travel experience (e.g., dining options and optional excursions) and the factors that influence such choices. A relatively small number of scholars have attempted to study customers during their consumption experiences through ethnographic research (Curtin, 2010; Curtin \& Wilkes, 2005; Lugosi, 2007; Saniford \& Seymour, 2007). Such research has provided rich data and expanded the knowledge of consumer behavior in the hospitality industry.

At the present time, research on hospitality guests, in general, and on tour travelers, specifically, focuses on the mature segment. Consequently, more research is needed to gain a deeper understanding of the travel behaviors of young travelers. Recently, Gardiner, King, and Grace (2012) proposed that travel decision making is generational in nature. They further suggest that the formative referents (experiences growing up) have an impact on travel decision making. Chiang, Aikaterini, Tang, Shin, and Morrison (2014) discovered that members of different generations utilize different information sources when planning a trip. Hritz, Sidman, and D’Abundo (2014) studied Generation Y perceptions toward health and wellness travel. They concluded by creating sub segments of the young travel market based on their attitudes toward health and wellness. Today, mature travelers still comprise the majority of leisure travelers; nevertheless, young travelers are a sizeable and growing market. In the United States, the U.S. Travel Association estimates that the average age of a leisure traveler is 47.5 years old. Still, individuals between the ages of 18-24 and 25-34 years comprise $8 \%$ and $20 \%$ of the leisure market, respectively (U.S. Travel Association, 2013). Petrak (2011) claims that the young travel segment represents 136 billion dollars in revenues to the global travel industry. She further adds 
that Generation $\mathrm{Y}$ will soon emerge as the best customers with respect to travel and leisure experiences, as they spend freely during such experiences.

The present research, which seeks to expand upon the current body of literature as well as to create new knowledge, seeks to gain a better understanding of the consumer behavior of young travelers (in their 20s and 30s). More specifically, the present research studies the group dynamics, preferences of AIO, as well as the decision-making process of young adults. Through an ethnographic study of such travelers, I gained useful information regarding patterns of preference, decision making, and group formations during the course of a 3-week journey. The research objectives are as follows:

- Explore the psychographic preferences of young travelers.

- Gain a better understanding of en-route purchase decisions.

- Understand group dynamics (including customer-to-customer interactions) among tour participants.

- Examine the role of the tour guide.

\section{Literature Review}

\section{Customer-to-Customer Interactions and Psychographics}

Service providers can play a critical role in the enjoyment and satisfaction of customers. Similarly, customers can influence their own levels of satisfaction and enjoyment during a travel experience. Conscious of this reality, researchers have studied customer-to-customer interactions (Huang \& Hsu, 2010; Martin \& Pranter, 1989; Wikström, 1996; Wu, 2007). Previous findings highlight the importance of managing such interactions in order to obtain a pleasant product or service. One of the earliest studies on customer-to-customer interactions was conducted by Martin and Pranter (1989). The authors argued that customers affect each other's experiences 
through verbal exchanges, appearance, and demeanor. In light of this, they proposed the concept of compatibility management. Formally defined, compatibility management is "a process of first attracting homogeneous customers to the service environment, then actively managing both the physical environment and customer-to-customer encounters in such a way as to enhance satisfying encounters and minimize dissatisfying encounters” (Martin \& Pranter, 1989, p. 7).

It has been proposed that the specific service environment, as well as the heterogeneity of customers, can determine the impact of customer-to-customer interactions. Martin and Pranter (1989) proposed that such interactions are more critical when customers are in close physical proximity to each other, when verbal interaction is more likely, and when they are engaged in numerous and varied activities; interactions are also critical when the service environment attracts a heterogeneous customer mix, the core service requires compatibility, and customers must occasionally wait for the service. Many of the various industries that make up the hospitality specialty meet many of these criteria due to the intangibility of the service, as well as to the importance of human interaction. Additionally, customer heterogeneity can be important when experiencing a service: Customers who have heterogeneous preferences, goals, and beliefs, as well as differences in past experiences and variability in physical characteristics and medical conditions, might be more varied from one another more often, and thus likely to experience potential dissatisfaction (Martin \& Pranter, 1989). In support of this observation, Johnson and Grier (2013) suggest that elements of cultural compatibility, intergroup anxiety, and cross-group contact can affect a customer's satisfaction within a service encounter. Research by Martin and Pranter (1989), as well as that by Johnson and Grier (2013), propose various critical aspects to the compatibility of customers in various service settings. Despite its importance, such research 
is mostly conceptual; consequently, both qualitative and quantitative research that illuminates the workings of customer-to-customer interactions could expand the field of knowledge.

$\mathrm{Wu}$ (2007) proposed that customer satisfaction is influenced by customer-to-customer interactions. Furthermore, it was Wu's (2007) contention that homogeneity among customers has a positive impact on the evaluation of fellow travelers' satisfaction. The author used a framework developed by Martin (1996), which included the following types of incidents: protocol and sociable incidents (which include benevolent acts, such as making good conversation, congratulating, shaking hands); violent incidents (which include being angry, kicking a chair); grungy incidents (such as lack of personal hygiene); malcontent incidents (including being upset after receiving bad service); crude incidents (such as making off-color jokes or abusing alcohol); and inconsiderate incidents (such as uncivil behavior). Wu (2007) proposed that travel companies can actively manage their customer-to-customer interactions by appropriately grouping customers with similar characteristics (homogeneity), communicating the code of behavior prior to the start of the trip, and actively preventing dysfunctional customer behavior from multiplying. While Wu's (2007) propositions can provide guidance to travel companies and help ensure customer satisfaction, organizations are not always confident about their ability, nor do they always have the desire to educate their customers. Consequently, the present study explores the extent to which the travel company, through its literature, orientations, and interactions with the tour guide, was able to successfully educate their customers and promote heterogeneity and satisfaction.

Research suggests that customers can be co-producers of products and services (Wikström, 1996). When customers have a great deal of interaction with the producer, their feedback can influence the design, production, and marketing of a product or service (Wikström, 
1996). According to Chathoth, Altinay, Harrington, Okumus, and Chan (2013), the logic behind co-creation "has been built on the premise that service forms the foundation of value creation through which customers are intensely engaged in every stage of the value creation process" (p. 11). In the delivery and receipt of services, customers are typically present and can exert significant influence on the ultimate outcome. In analyzing a tour experience, Prebensen and Foss (2010) describe how various events during the course of a tour experience made tourists change their plans and preferences. In addition to the interaction between the service provider and the tourists, the presence of others will also shape the characteristics of the service and the experience received.

Customer-to-customer interaction can be of even greater importance in settings that offer many opportunities for interpersonal connections. One such setting is a cruise ship, where passengers share in dining, shopping, entertainment, and other activities with fellow cruise guests. In light of this, Huang and Hsu (2010) studied customer-to-customer interactions within a cruise setting and focused on interactions with previously unacquainted tourists. Their study revealed that such interactions have a positive and direct impact on the cruise experience and satisfaction among travelers. Furthermore, the authors proposed that it is the quality (as opposed to simply the quantity) of interactions that really matter to the overall experience. Such quality might be associated with the affective states experienced by the customers during their journey (Huang \& Hsu, 2010). The present research seeks to gain a better understanding of customer-tocustomer interactions in the setting of a European bus tour. As such, the amount of time spent together while sharing the service space and participating in group activities is likely to make the customer-to-customer interaction critical to the overall enjoyment of the travel experience. 
In the hospitality and tourism literature, a relatively small number of ethnographies have been conducted (as compared to other research methodology). Some of these ethnographies include some component of customer-to-customer interaction. For example, Curtin (2010) used an ethnographic approach to study travelers participating in wildlife tours. The aforementioned study focused on the purpose of travel and its environmental and social impacts, as well as the influence of travel guides and group dynamics among travelers. Another study, which examined the bar culture, was performed by Lugosi (2007). The study explored the role of customers in the production process within the setting of a gay bar. Wang, Hisieh, and Chen (2002) investigated the role of the travel guide/tour leader in the travel experience and purchase-decision process. Quiroga (1990) explored various factors that influence customer satisfaction within a tour group setting, such as travel motivations, expectations, group size, and group cohesion. In a similar vein, Grove and Fisk (1997) sought to understand the impact of customer-to-customer interactions using a critical-incident approach. Their study revealed that $56.8 \%$ of customers felt that other travelers significantly affected their satisfaction with a tourist attraction. These studies have advanced the field of knowledge and illuminated the understanding of guest interactions. However, it is noteworthy to state that many tour and packaged experiences, such as the ones studied by the mentioned researchers, cater to a slightly more mature demographic. The present study seeks to expand upon the work surrounding customer-to-customer interactions by studying young adults during their vacation experiences.

The practice of marketing often requires market segmentation. One approach to such division of the market is to appeal to travelers on the basis of age. Backwell and Mitchell (2003) studied the impact of demographics (in this instance, gender) on the decision-making processes of customers. Another strategy is to appeal to travelers based on psychographic factors. 
Accordingly, customers can be categorized by their activities, interests, and opinions (AIO). Vyncke (2002) used the AIO framework to develop various typologies of consumers. The framework proposed that such segmentation, based on psychographic factors, can be more useful than traditional demographics in uncovering a customer's benefit or attribute evaluation. Galloway (2002) segmented park visitors based on psychographics. Accordingly, three attitude dimensions were introduced: enjoyment of nature, escaping stress, and sensation seeking. Veisten, et al. (in press) studied travelers to Norway and proposed segmentation framework composed of both demographics and psychographics. Mehmetoglu (2006) studied visitors to natured-based attraction with special emphasis on packaged tour versus non-tour visitors. The findings suggest that the two groups had different preferences when it came to their desired activities. Whereas independent travelers preferred short hiking tours, cycling, and fishing, tourbased visitors preferred activities such as shopping, sightseeing, and dining (Mehmetoglu, 2006). Formica and Uysal (2002) segmented travelers based on their environmental attitudes. Accordingly, three groups were proposed: conservationists, anthropocentrics, and optimists (Formica \& Uysal, 2002).

The present research sought to evaluate the decision-making processes among young travelers, as well as their grouping based on psychographic factors, namely their activities, interests, and opinions (AIO). Whereas the tour company selected used a demographic approach, I expose some of the challenges associated with simple demographic segmentation and highlight the different psychographic preferences of customers, which can potentially be used to devise a more targeted segmentation strategy. 


\section{Decision Making}

Consumers are involved in a series of decisions regarding their travel experience. Some of these decisions are made prior to the beginning of the trip; others, however, are made during the course of travel. The current literature sheds light on the pre-purchase decision process. Much less attention has been paid to the decision processes that take place during the enjoyment of the travel experience. Choices are made by consumers at various stages of the decisionmaking process. Martin and Woodside (2012) support this notion by stating, "Once at the location, more decisions are made as the trip unfolds" (p. 856). Choi, Lehto, Morrison, and Jang (2012) suggested that earlier travel decisions affect those made later in the process. Furthermore, the authors termed such decisions en-route decisions (Choi et al., 2012). Whereas the multitude of consumer decision-making theories shed light on consumer behaviors associated with purchase choice, they do not always stress subsequent choices. Many theories also stress the individual decision process and do not pay enough attention to group decision processes. Prebensen and Klevien (2006) suggested that there are two groups of customers: decision makers, and non-decision makers. Decision-makers often make choices themselves, whereas non-decision makers typically followed other people's decisions.

Decrop and Snelders (2005) followed the decision-making process of 25 Belgian households for a year. Some of these consumers traveled alone or with their significant others, groups of friends, or their respective families. Based on their research, a socio-psychological typology was developed to explain their decision-making process. Their typology categorized travelers as:

- habitual vacationers, who repeat the same vacation every year and thereby avoid risk and uncertainty; 
- bounded rational vacationers, who are thrifty, pragmatic, and careful planners;

- hedonic vacationers, who seek pleasure and emotional arousal, and who are more driven by their dreams rather than by practical concerns;

- opportunistic vacationers, who do not engage in much planning, but rather will take advantage of unanticipated opportunities to travel;

- constrained vacationers, who are limited by financial resources and situational factors; and

- adaptable vacationers, who make vacation plans, but are constantly modifying based on new information.

In addition to the typology, Decrop and Snelders (2005) concluded that the decisionmaking process is ongoing. Therefore, vacation decisions surpass the initial pre-travel planning and extend to choices made during the actual enjoyment of the vacation experience. Consequently, one decision made at an earlier stage can influence choices made at alternate stages of the travel experience.

In order to explore vacation decision making, Chernev (2004) proposed that consumer decision making is largely influenced by the individual's goal orientation. Therefore, products and services that are consistent with such an orientation will likely be selected in the marketplace. In a different study, Mansfeld (1992) proposed that such motivation is influenced by both the customers' stated preferences and information-gathering strategies. Various product or service categories can entail different criteria for customer decision-making. For example, Duarte Alonso, O’Neill, Liu, and O'Shea (2013) studied factors that influenced restaurant choice and determined that both prior experiences and a clean environment were of outmost importance. 
In the field of marketing, practitioners often segment travelers on the basis of demographics. Gardiner et al. (2012) proposed that generations have different values and attitudes, which may influence their decision making. In particular, the authors studied informational referents and normative referents, as well as the ways in which these impacted the consumer decision process among generations. The study, which used focus groups, identified the following formative referents: friends, family, religious affiliation, socioeconomic circumstances, education opportunities, employment opportunities, the economy, and social value (Gardiner et al., 2012). It was found that “informational referents inform the consumer's perceptions of the hedonic value of travel...hedonic value expectations about the travel experience in turn influence a consumer's purchase attitude and intention" (Gardiner et al., 2012, p. 319.). The present study explores decision-making processes within groups and subgroups created during a tour. More specifically, the study examines young travelers making en-route decisions. As such, it expands the field of knowledge and grants further evidence for the decision processes among travelers.

\section{Methods}

The present research used an ethnographic approach to study young travelers. In the field of sociology, ethnographies are popular due to their ability to capture rich information about the subjects. In business and hospitality research, ethnographies are less common. Nevertheless, a small group of researchers has used this social science qualitative approach, with an emphasis on customer-to-customer interactions, for their research. For example, Lugosi (2007) examined bar culture and the role of customers in the production process of a gay bar setting. Quiroga (1990) observed the group dynamics, group cohesion, and travel motivations among travelers to Europe. Finally, Curtin (2010) used an ethnographic approach to study the wildlife tourism experience. 
The present research explored the decision-making processes, psychographic preferences, and group dynamics in a tour-group setting. Since one of the aims of this study was to examine customer-to-customer interactions, I chose to employ an ethnographic approach. Bowen (2008) argues that "participant observation is a technique that, in certain circumstances, can lead to a fuller understanding of thoughts, actions, and feelings than some more conventional research techniques" (p. 1515). Although the purpose of the method is not to do statistical generalization, ethnographies allow the researcher to conduct analytical generalization (Bowen, 2008). Furthermore, Seaton (2002) highlighted the usefulness of conducted tours for tourism research by calling them "tourism's hermetically sealed traveling laboratory" (p. 311). Using other methods to examine customer-to-customer interactions is possible, but an ethnography allowed me to examine the full complexity of consumer behaviors in real-time and to have ready access to actual travelers. Corporations often limit customer access for fear of disrupting the customer experience or of having their proprietary information disclosed. Consequently, an ethnographic approach allowed me to gain full access to travelers during their vacation. Additionally, the covert nature of the study, allowed me to obtain candid reactions from customers as they interacted and co-created the service experience.

Unlike previous studies on tour groups, which, for the most part, comprised a mature audience, this research focused on young travelers in their 20s and 30s. In order to study such a group, I searched for tours that specialized in young travelers and decided to book with a popular tour company that appealed to such a market segment. The company defined young travelers as those between the ages of 18 and 35 years old. The tour was a 21-day trip through various European cities, with a starting point in London and an ending point in Paris. Over the course of the trip, seven different countries and ten cities were visited. The tour had a similar route as 
compared to tours offered by competitor travel companies. In consultation with a reservation agent, I ascertained that this was one of the most popular tours offered by the travel operator. A total of 50 young travelers joined this trip during the summer of 2013. It has been argued that the use of ethnography can provide a rich understanding of consumer behavior (Bowen, 2002). Consequently, the present study intended to explore the previously mentioned topics from a deeper perspective by observing young tourists during their enjoyment of the travel experience.

Prior to the start of the journey, I sought and obtained approval from the University Internal Review Board (IRB). In my request, I explicitly expressed my intention to conduct such research in a covert fashion. In the past, other hospitality and tourism researchers have conducted research in a covert fashion while using a complete participant approach (Bowen, 2008). Lugosi (2006) suggested that the choice of covert versus overt data collection should take into account the fieldwork context, the relationships between the researcher and the subjects, and the nature of the study. Furthermore, conducting research in a covert fashion may also grant access to information that would otherwise be denied to the researcher (Lugosi, 2006). Another key advantage of covert data collection is the potential for more candid responses and interactions. When participants know that they are being observed, the potential always arises for individuals to monitor their comments and behaviors and to express socially desirable views. In previous research, Lugosi and Bray (2008) utilized both covert and overt methods of ethnographic inquiry. They noted that, when observing the tour guide in an overt fashion, it was clear that he or she moderated behaviors as a consequence of being observed. Therefore, the researchers opted in favor of a covert approach to continue their study of other tour guides (Lugosi \& Bray, 2008).

Presenting an opposing viewpoint, Shils (1982) suggested that covert methods violate an individual's right not to be studied. Nevertheless, this and many other hospitality ethnographies 
take place within the context of public spaces and observe interactions that would be observable to other guests and service providers. In discussing the ethics of covert participant observation of tour groups, Lugosi and Bray (2008) stated that "the public nature of the walking tours and the practice of tour guiding meant that the study was less vulnerable to criticisms of invasion of privacy" (p. 471). Calvey (2008) argued that, in social science research, all the probabilities cannot be accounted for by a consent form. Consequently, every research (whether covert or overt) carries a semi covert component. Furthermore, the author argued that medical models of research might not always be perfectly applicable to social science research (Calvey, 2008). Covert research also brings forth the challenge of anonymity. In order to protect the anonymity of the subjects, the researcher uses pseudonyms to describe them, and did not disclose the name of the specific travel operator, name of the tour, specific dates, and other information that would help identify specific people within the tour. Lugosi (2006) proposed that "the critical questions for ethnographers do not simply concern how they engage with informants, but how they distinguish between those concealments that are necessary or unavoidable in these relationships and those that represent dangerous or irresponsible moral transgressions" (p. 257).

A more overt research approach would have granted me the opportunity to conduct formal, structured interviews with the participants. In order to overcome this limitation, I took advantage of the opportunities in which individuals voiced their opinions about the tour, participants, decisions, and other relevant data, to ask additional questions and to gather further data. This part required me to ask questions in a more conversational and informal manner. Most relevant data took place during the course of day-to-day interactions within the tour. In describing his method for data collection during an ethnography, Bowen (2002) mentioned making field notes in a notebook, letter papers, and postcards, as well as reviewing still 
photography, to help with recollection. For the purposes of the present research, I followed a similar process by taking notes on a daily basis. Simple notes and observations were taken throughout the day via smartphone. At the end of the day or at the beginning of the following, I would write more detailed entries. Some of these entries were made in the privacy of a hotel room, whereas others were made during some of the long bus journeys. Since several tour participants carried a travel journal or diary, I appeared to be carrying out the same activities as the rest of the tour participants. Additionally, photographs were taken and later reviewed to help with the recollection of specific events. Bowen (2008) argued that an ethnographer can take on a wide or close focus. In his research, he utilized both by starting with wide observations and then making more closely focused observations and casual questioning. During the course of this study, I utilized both approaches, as well.

At the time of the study, I was 30 years of age and an assistant professor at a university in the United States. Given the age similarity, I was able to embed myself in the tour group. Seaton (2002) compares the role of the researcher in both open and closed situations as follows:

While the researcher as observer in the open context situation is always, ultimately a stranger in another culture, in the former s/he may be accepted through seeming to be a co-equal - as, in this instance, a member of the touring party. (p. 312)

In the context of this particular research, it was my intention to make myself be seen as a member of the tour. The tour selected was a 3-week European tour. The length of the trip facilitated a number of interactions greater than that which might have been experienced during a shorter excursion. The majority of the participants were from Australia and Canada, and a few were Americans and New Zealanders. The field notes provided a rich source from which to identify patterns and to analyze data. After the journey, I examined the research notes and 
identified trends. In doing so, I utilized both inductive and deductive approaches. Information from previous research and management theory helped my interpretation of the facts. Additionally, I partially utilized a grounded theory approach, whereby patterns are drawn from the data themselves. Charmaz (2004) proposed that grounded theory is a series of inductive procedures aimed at developing theory. In placing such an approach into practice, a researcher begins with cases and experiences and eventually develops these into more abstract categories, which should aid in explaining patterns and relationships within the data (Charmaz, 2004). Information was clustered into themes and relevant meaning units, which is consistent with prior ethnographic research such as that conducted by Curtin (2010). After relevant incidents and themes were identified, I proceeded to write the findings of the study.

\section{Ensuring Quality Observations}

In order to ensure the quality of the research, I took various safeguards and exposed my research to a variety of logic tests. . In doing so, I followed the framework proposed by Guba and Lincoln (1982), which include examining the credibility, transferability, dependability, and confirmability of data. With regards to ensuring the confirmability of the study, I used various methods to take notes and to help with the recollection process. First, via smartphone, I took brief notes throughout the day. Second, each day I would take extensive field notes in paper form. Third, I verified still photographs to help recollect certain people or events. Third, I reread the notes several times and reflected upon the data before coming to any conclusions. In terms of credibility, I spent a prolonged amount of time with the tour, with most of my time (excluding sleep) spent with the group. I spent approximately 14 hours daily with the tour group for a total of 21 days, which would account for 294 hours of observation. Consequently, I was able to 
observe similar behaviors take place on several occasions. For example, participants had to make decisions regarding optional activities, choice of restaurants, and other important en-route decisions several times throughout the journey. I also employed source triangulation by inquiring about the opinions of various members. For example, when reflecting upon the tour guide and the driver, I was able to hear statements of various group members, which gave me a more complete perspective. I also employed peer debriefing, by consulting with a senior faculty member at my university after completing the first draft of the paper.

Dependability was ensured by overlapping methods and time triangulation. Observations were made and informal interviews were conducted to obtain similar information. Data were also gathered at different points during the journey. The transferability of this research is enhanced by giving a thick description, in other words, by ensuring detailed accounts of the information, especially in the results section. Additionally, I have furnished information about the trip setting, length, participants, and other relevant data. Finally, I have presented the viewpoints of various members as they interacted with one another. In addition to the traditional elements sought in a superior qualitative piece, I took extra precautions not to present a biased account of events. Throughout the course of the data collection and analysis, I asked whether any of my own personal characteristics were creating a biased perspective, including: culture, religion, age, travel experience, and education. Although, as a researcher, I am expected to draw on my prior knowledge of consumer behavior and hospitality, I made sure, through constant reading, writing and rewriting, that any bias was minimized.

\section{Findings}

\section{The Start of the Journey}


In anticipation of the beginning of the trip, the tour company encouraged participants to communicate through their own social media outlets. Many of the young travelers expressed feelings of excitement and anticipation. Some expressed the desire for adventure, while others communicated their intention to party. On day one, the group met at a designated location. At first, people sat quietly next to each other. This occurrence did not last long, as one of the tour participants broke the ice by introducing himself. The first introduction, in turn, led to a cascade of introductions. Basic topics covered included names, place origin, and the length of the trip en route to the destination, as well as a few commonalities. After a formal introduction and a brief orientation, the group proceeded to have dinner and a few drinks at a nearby pub. I quickly noticed how tour participants altered the space in the pub by switching the table configuration in order to accommodate the emerging groups.

On the second day of the tour, participants met in front of the tour bus. Once inside the tour guide, Andrew (pseudonym) spent nearly 2 hours on giving an extensive briefing about the trip. Some of the information given during the briefing reflected his prior experiences, benefits, challenges, and troubles while traveling with a group of young people. In previous research, Curtin (2010) highlighted the importance of the tour guide to the overall trip experience. The guide himself was a young man, in his late 20s, who originated from Australia but had traveled extensively throughout Europe and other parts of the world. Although many found this briefing helpful, some thought it was too long. Later during the trip, Catherine would remark that Andrew “talks too much.” The briefing also contained additional information about safety, civil behavior, and travel itineraries. Furthermore, the tour guide made a good sales effort by promoting the optional tours and excursions. These tours were meant to both enhance the travel experience and 
generate additional revenues for the travel company. Wang et al. (2002) stress the role of the tour leader as a promoter of excursions.

\section{The Groups and Their Interactions}

Previous research focused on customer-to-customer interactions (Huang \& Hsu, 2010; Martin \& Pranter, 1989; Wikström, 1996; Wu, 2007). The present study examines such interactions within the context of a European tour group. The tour allowed each participant to travel with a friend, sibling, spouse, or significant other. About two thirds of the people in the group traveled with another person; the remaining one third traveled by themselves. The tour appealed mostly to travelers in their 20s and 30s. The age range made for a series of differences. First, some were in college or had recently finished college, whereas others were young professionals. Some paid for their own trip, whereas others were given the trip as a gift from their families. This particular tour included several married and engaged couples. There were even two couples who used the tour as their honeymoon trip. Although this trip is not marketed for the purposes of a honeymoon, some young couples thought it would serve as a good honeymoon, or at least as a good part of their honeymoon. Later during the trip, one of the single travelers remarked, "who would go on this tour during their honeymoon"? Although there were some differences among tour participants, there were also some similarities. Tour members, by way of the tour operator's requirement, were all in their 20s and 30s. The young travelers were

also predominantly from two countries: Australia and Canada. All members spoke English, with most of them speaking it as their primary language. Finally, based on their occupations, education, ownership of objects, and other characteristics, I would place most members in the middle class. 
Group formation was an important aspect of the tour experience. Previous research suggests that the need to belong is a fundamental human motivation that guides voluntary and involuntary behaviors, thoughts, and emotions (Baumeister \& Leary, 1995). Furthermore, previous ethnographic research had signaled the formation of subgroups (Seaton, 2002). A few days into the trip, it became clear that some groups had already formed. Although people moved from their main group from time to time, there was a definitive group membership. At times, group membership occurred based on similar interests, on nationality or culture, or on previously made acquaintances (some members traveled with friends, siblings, or significant others, thus helping the formation of groups). Some of the groups are presented in Table 1. Later in this paper, I will discuss the various critical incidents involving the groups.

\section{>> Insert Table 1 Here $<<<$}

One of the groups that formed very early in the trip was that of Tess, Teresa, and Travis (the mature group). These three individuals had different occupations and personalities. However, they were all in their early 30s, which placed them at the upper threshold of ages for the tour group. Overall, the group was very sociable, though later during the tour, Tess confessed that "the three of us have been like a clique during most of the tour." Tess, Teresa, and Travis liked to enjoy each of their destinations, but, as a general rule, did not stay up as late, or party as much, as their younger counterparts. I enjoyed a few opportunities to interact with the mature trio. In one interaction, Travis confessed that the presence of so many couples changed the group dynamic for the single people in the trip. Tess seemed to agree that it would have been preferable to have more single, and slightly older, fellow travelers. Martin and Pranter (1989) introduced the concept of compatibility management as a way of generating better interactions among homogeneous group members in a service encounter. The interactions between the mature group 
and other group participants may have been rendered more pleasant had the tour company made a greater effort to ensure greater compatibility among tour participants.

Travis was openly gay and shared that with people in the group. He also confessed to me, as well as to the members of the mature group, that other tour participants often consulted with him and asked his opinion regarding the sexual orientations of other tour participants: "People keep asking me whether I think (blank) is gay." Travis' account gave the impression that he was somewhat amused — and somewhat annoyed — by such inquiries. Another person who traveled alone was Susan. Susan once shared that, although she was at times invited to join some of the couples, she did not know how to act: "I feel awkward hanging out with the couples; I don't know if I'm imposing."

Having spent a significant amount of time and resources, the young traveler's experience was often affected by an unknown factor: the roommate. Single travelers on the tour had the option of sharing a room with another person or paying extra for a single room. Wanting to avoid the risk of an unknown roommate, I decided to take a single room. Many of the travelers who shared a room with a previously unknown fellow traveler shared several concerns. Tess complained that her roommate, though a wonderful person, snored very loudly. Travis stated that his roommate often drank late at night and would wake him up upon his arrival to the room. These incidents, in turn, affected the enjoyment of the overall experience.

One of the largest groups that formed early in the trip was that of the Australian siblings, their significant others, and two other Australian couples who joined forces (hereafter referred to as the "Aussie siblings and company"). I met this group early on our journey, as they took a ferry from England to continental Europe. After reflecting on the factors that united this group, I concluded that family ties, cultural affinity, and similar interests bonded this group. For example, 
three of the group members were siblings, thus supporting the idea of family ties. Secondly, most members were of Australian origin, which created some cultural homogeneity and facilitated cohesion within the group. Third, the group had similar interests, which facilitated spending greater amounts of time together throughout the journey. Consistent with these ideas, previous research suggests that both frequency and stability are essential components of the need to belong (Baumeister \& Leary, 1995).

Among group members, I was the only non-Australian who joined the Aussie Siblings group on a regular basis. Throughout the trip, I made an attempt to participate with various groups, but overall, I would identify this particular one as the primary group during the journey. The group, as a whole, enjoyed sightseeing, good meals, and an occasional party. There was not a strong interest in activities that were more culturally oriented, such as visits to art galleries and museums. Therefore, on occasion, I would leave the group's company, especially when compelled to enjoy the cultural aspects of the destinations visited. Although the group did some shopping throughout the trip, this did not seem to be a strong interest, compared to other groups. Based on their occupational choices and their educational backgrounds, members of this group can be considered a part of the middle class. This highly cohesive group spent a significant portion of the tour together and seemed to function well, with minimal conflict. Janis (1982) suggests that highly cohesive groups are characterized by friendliness, mutual liking, cooperation, and motivation in carrying out group tasks. All these factors were observed throughout the tour. Members helped each other navigate their way through the different cities, complemented each other, and made sure that everyone was included for group activities. During the course of the trip one of the group members Brian received news that his father passed away. Shortly thereafter, he and his wife Alice took a flight back to Australia, thus leaving the tour. The 
group was very supportive to the young couple and demonstrated their care. Towards the end of the journey, a group picture was taken. In this picture, photographs of Brian and Alice were held by others, as to indicate that they were still members and still being thought of. Despite this incident, the group continued to be united during the tour.

Shared experiences during this trip helped to cement the friendships that ensued. One of the first activities in which we participated was a bike tour in a small town near Amsterdam. On a personal note, I admit that I had not ridden a bike in many years. Consequently, the first few minutes presented a struggle to find balance. This experience served as some moments of fun for the group (at my expense), but also made some group members observant of others and created memorable events. During the tour, the tour guide often played a song at the beginning of each bus ride. The theme song became yet one more way to create a sense of group identity and belonging. Toward the end of the trip, members knew some of the lyrics and sang aloud.

Throughout the trip, one traveler spent a good portion of time on his own. For the purposes of this paper, I will call him Sam. Sam was the only other traveler to come from the United States. Based on his education, occupation, and ownership of specific items, I would place Sam in the category of upper-middle class. Though he shared transportation and a room with other travelers, every opportunity for free time (outside of the schedule), he took to explore on his own. He had various paper travel guides and audio guided tours that he downloaded from a popular travel site prior to his arrival. Sam had a professional-grade camera and took many pictures. As a part of this tour, another traveler, Carl, who was a professional photographer, carried similar equipment. Sam once told me that "the only person in this tour that I would allow to use my camera is Carl." Throughout the trip, many participants in the group commented that it was uncivil for Sam to spend all the time on his own and to not share it with the group. 


\section{Decisions, Decisions}

A key observation from this study was the ways in which the consumer decision process worked for travelers. Martin and Woodside (2012) proposed that the travel purchase decision does not conclude with booking the trip, but rather continues during the travel experience itself. During the tour, travelers had to choose optional excursions. Many of these excursions were marketed through a company's website, as well as in travel-related literature. However, the final point of contact was the tour guide. One of his many roles was to entice and to help promote such options. This is consistent with the work of Wang et al. (2002), who stress the idea of having the tour leader function as a promoter of various packaged experiences. The tour guide came across as very knowledgeable and very sincere in his representations of the various items. Throughout the tour, he visited individually with travelers to aid them in planning a vacation that was, given the limitations of group travel, as personalized as possible. Andrew stated that he tried to avoid "plastic and fantastic tours" offered by other guides.

On the second and third days of the trip, travelers had to make most of their optional tour selections. Immediately after the options were presented by the tour guide, a cascade of interactions started to occur. People consulted with each other as to the excursions each would like to take. Tour participants shared their opinions as to the desirability of each option and who else might be participating. I also found myself asking others which tours they would choose, and why. Of particular interest, when I asked a member of the Aussie siblings and company, he replied, "You might want to check with Alice," who seemed to be the most influential decision maker in that subgroup. Throughout my observations, as well as throughout unstructured interviews with various participants, it seemed clear that travelers make their optional tour choices based on (a) their objectives (what they wish to get out of the trip, whether it is 
adventure, culture, or celebration among others); (b) their interests (whether the individuals are more interested in cultural activities, culinary experiences, or physically demanding events, among others); (c) budget (some team members had extensive cash and resources to pursue options, while others were constrained by a tighter budget); and (d) the decisions of others (especially those most influential to them-opinion leaders in the tour, those who traveled with them, etc.).

A good portion of each day was structured by the tour company. However, there was some degree of free time in most of the cities visited. Free time was used in different ways by various people. Some travelers preferred to do the most they could in a single day by packing in various activities. Others simply liked to walk and soak up the scenery of each destination. While some researchers and practitioners might consider the young traveler market to be homogeneous, it was the researcher's observation that they were not as similar as previously thought. For example, some travelers preferred to have an upscale dining experience that reflected the culinary tradition of the area, whereas others searched for a quick and inexpensive meal that would allow them time to focus their efforts elsewhere. In light of this, psychographic segmentation or segmentation based on the activities, interests, and opinions (AIO) is particularly relevant. Vyncke (2002) studied psychographic segmentation and its relevance to consumers and their media preferences. Further research has supported the use of psychographics in the hospitality and tourism industries (Mehmetoglu, 2006). Segmentation based on psychographic factors can aid tour companies in identifying people with similar interests, opinions, and preferred activities.

Despite the amount of scheduled time in the tour, some free time afforded participants the opportunity to make various travel decisions. For example, groups frequently struggled with their 
choice of a restaurant for lunch. They often walked to various places throughout the city and studied menus. The decision became more complicated when people had different objectives. For example, some travelers wanted to experience a fine authentic meal, whereas others were limited by their budgets. In addition, some preferred healthier options, whereas others were not highly concerned with healthful eating. After spending several days eating the local food of one of the countries, Susan remarked, "I don't want any more [type of local food], I just want a salad." Decrop and Snelders (2005) suggested that the decision-making process is ongoing. As seen in the case of this particular tour, decisions were a matter of daily life en route. The type of decisions and factors affecting such decisions can potentially contribute to the enhancement of the travel experience.

\section{The Social Lubricant}

Some have described alcohol as a social lubricant - as a type of magical fluid that facilitates interaction among individuals. The tour was no exception. Previous research highlights the increased alcohol consumption of travelers (Josiam, Hobson, Dietrich, \& Smeaton, 1998). Furthermore, the negative aspects of tourism, such as alcohol consumption and its effect on public order, have been documented in previous research (Haukeland, 1984). In a previous ethnography of tour guiding, Lugosi and Bray (2008) noted how the tour company offered a pub crawl tour. It was argued that guests were encouraged to consume alcohol in order to amuse group members. During the course of the tour, I observed that the amount of alcohol consumption varied greatly from person to person. The usual routine for the tour was to spend two nights in every city, and then move to the next. People quickly learned that, on days in which the tour traveled from one city to the next, there were many hours spent on the bus. 
Consequently, many stayed up late the night before a travel day. On the bus, they took the opportunity to catch some much needed sleep before the next destination. Out of respect for the sleeping travelers, the tour guide would not commence his talking until at least 1 or 2 hours into the drive (drives ranged from 4 to 8 hours each travel day). After a few days, travelers became aware of those who would drink the heaviest and thus be hungover on the bus. Therefore, those who drank the least made a point to avoid such individuals during the bus ride.

One of the single travelers, Susan, was typically a very shy and reserved woman in her late 20s. Later during the trip, Susan began to join the parties and drinking. Despite her petite size, she impressed others with her ability to consume alcohol. Several group members commented that she seemed like a different person when she drank. For example, at a karaoke bar, Sandra took the stage after having a few drinks and served as a backup dancer for whoever was singing at the time. Overall, she seemed to be more outgoing and affectionate during such evenings. One day at a café, Susan confessed to me that she suffered from anxiety. Perhaps the alcohol served the purpose of relaxation and aided in helping her enjoy the tour's activities uninhibited.

Although alcohol served at times as a social lubricant, it also served to create some tensions among the tour. This was particularly true on our departure from Munich. Our bus left early in the morning. After everyone was seated, the tour guide counted people and quickly realized that there was someone missing. Howard, one of the drinking buddies, was not present. His friend Hank told the tour guide that he had tried to wake him up, but that he could not do so. Noticeably upset, the tour guide went inside the hotel and proceeded to go into Howard's room. Later on, we came to find out that the guide had to get Howard out of bed, as he was still asleep. As Howard approached the bus, many of the travelers in the bus made fun of his demeanor. 
Howard seemed very tired and sleepy, and dragged his feet all the way to the bus. Some travelers noted that his behavior was very uncivil, as he delayed the departure time. Andrew, the travel guide, was visibly upset by the incident. He remarked that he normally would have left, but since it was Howard's birthday, he'd made an exception. One of the tour members (Angela) was a physician; consequently, members often asked her health-related questions. Toward the end of the trip, Hank observed, "My skin is turning yellow," to which Angela replied, "It's probably your kidneys; you need to make sure to drink lots of water."

\section{The Tour Guide and the Driver}

The role of the tour guide can be critical to the enjoyment of the travel experience, as well as to the attainment of the travel company's objectives. During the course of the trip, I spent a significant amount of time in close contact with the tour guide and the driver. Furthermore, I was able to ascertain the group's opinion of their performance during various conversations. Andrew, the tour operator, is in his late 20s and originally from Australia. A world traveler and nomad, Andrew is also a veteran of the travel industry. In fact, Andrew has spent about 5 years working as a tour guide, although the average tenure of a guide within this company is about 2 years. Presumably, the high turnover is attributed to the long hours, time spent away from home, and the stress associated with traveling with 50 tourists each day. On this particular tour, the tour guide worked continuously for 3 weeks with no days off. A prior study by Ap and Wong (2001) called into question the perceived glamour of the profession. Accordingly, many tour guides lack an established career path, have limited training opportunities, and incomes that vary according to the amount of gratuities received. Wang et al. (2002) explored the role of the travel guide/tour leader in the travel experience and purchase decision process. Throughout the course of the journey, one of Andrew's critical roles was to sell optional excursions. Such excursions were 
meant to both enhance the travel experience as well as to generate additional revenues for the travel company.

As a part of the research, I posed several questions of interest to the tour guide. One of the questions regarded the training offered by his company. In previous research, Lugosi and Bray (2008) examined the training of tour guides in an entrepreneurial travel company. Initially, guides were trained by the owners, who followed them on various tours. Later, as the company grew, new tour guides were paired with experienced ones in order to observe them during the execution of the tours (Lugosi \& Bray, 2008). Andrew told me that he went on a trip with a few other prospective travel guides. The trainer required them to learn facts about some of the major European cities and then make mock presentations. Overall, the training was unstructured. Andrew confessed that he perceived that the main purpose of the training was to ascertain whether the prospective guides would survive the daily life of a tour guide. Consequently, they were placed under constant stress and given very little sleep throughout their training periods. Tour guides can play a critical role in generating authentic experiences for their guests (Reisinger \& Steiner, 2006). During the course of the trip, Andrew had the opportunity to craft some aspects of the tour as well as his presentation according to his own criteria. When addressing the travelers for the first time, Andrew indicated that he tried to stay away from "plastic and fantastic" tours offered by other guides. When addressing the travelers for the first time, Andrew indicated that he tried to stay away from "plastic and fantastic" tours offered by other guides. In light of his statement, Andrew strived to demonstrate the real culture, cuisine, sites, and history of each location. He was known for his enthusiastic style, and the group members would familiarize themselves with phrases he constantly used, such as "right in the heart of it." 
The driver for the majority of the trip was Roberto, who was originally from Portugal, a veteran motor coach driver, and approximately 42 years old. Roberto seemed very knowledgeable about the roads to each major city we visited, as he never was lost. Furthermore, he made strides to make sure that the transportation from one major city to the next included stops where we could experience some additional sightseeing. In addition to speaking Portuguese and English, the driver also spoke Spanish. Therefore, the researcher was able to have various conversations with him in Spanish throughout the trip.

In one conversation with Trevor, Tess, Theresa, and Lindsay, I was given some feedback regarding the performances of both our tour guide and our driver. It was the group's opinion that Andrew was very energetic and dedicated. This was evident by the amount of time he took to move through the motor coach and touch base with everyone by asking whether they had any questions about the city, local attractions, or how to get around. The group also thought that, at times, Andrew seemed to have a short fuse. This became evident in Rome. While presenting some information on the street in front of a major tourist site, a street vendor approached him and the rest of the group several times. He became angry, pushed the street vendor, and said, "Go away; I had a gypsy like you steal my bag before." Later, I learned that a street vendor had stolen a bag full of personal items and some cash belonging to the company during one of Andrew's previous tours. Tess, Theresa, Trevor, and Lindsay added that Andrew exhibited parent-like behavior when admonishing some group members for uncivil behaviors.

Regarding the perceptions of the bus driver, most people (especially those with whom the researcher had a performance conversation) thought he was very professional and was very knowledgeable about his job, the roads, and major attractions. This was demonstrated by Roberto's professional attire and demeanor. Every morning, Roberto cleaned the bus thoroughly. 
In fact, sometimes he would clean the windows several times a day to ensure that the travelers were able to get the best possible view of Europe. He called the bus his "girlfriend" and used the metaphor to explain how dirtying the windows or trashing the floor was like touching his girlfriend or disrespecting her. At one point he stated, "If you touch the windows, it is like you touched my girlfriend's boobs.” In assessing his performance, the group (Tess, Theresa, Trevor, and Lindsay) thought the driver may have gone a little overboard with his performance. The overall purpose of the act was to explain some of the rules of civil behavior on the bus in a comedic way. For these purposes, the driver wore a pair of sunglasses and took out a water gun. He explained the rules in a very serious manner. Most of the people thought his hero-like performance was hilarious, while others took it seriously. After getting to know Roberto better, the researcher felt confident that his intention was to be humorous, but that perhaps he should have toned it down for the more sensitive ears in the group.

With many tours, the tour guide and the driver derive some of their income from gratuities. Tipping behavior has been studied in the hospitality and tourism literature. In fact, Tsaur and Wang (2009) studied customer satisfaction for tour groups that used various tipping systems. Toward the end of the trip, Andrew gave tour participants some empty envelopes for tipping both him and Roberto. This was to be expected, as the literature for the trip suggested a gratuity of 2 euros per day for both the guide and the driver. Andrew explained that he and Roberto received a modest salary, which was consistent with similar jobs elsewhere, from the tour company. However, the two made most of their income from travelers who expressed their gratitude through tips. Tipping was the subject of various discussions among the travelers. Before placing money in each envelope, they often consulted among themselves, saying, "How much are you tipping Andrew or Roberto?" For the most part, it seemed that travelers went with 
the suggested amount, though some had decided to tip lower or higher based on their tour experience and their perceptions of fairness with respect to the gratuity amount.

\section{Discussion and Conclusion}

The present research sought to gain a better understanding of the consumer behavior of young travelers. More specifically, I studied the group dynamics, preferences of activities, interests, and opinions, as well as the decision-making processes of young adults involved in a tour of Europe. Earlier in this paper, I proposed several research objectives, with one being to better understand group dynamics and customer-to-customer interactions among participants. The influence of other travelers can positively or negatively influence the vacation experience. In earlier studies, it was demonstrated that customer-to-customer interactions impact customer satisfaction (Huang \& Hsu, 2010; Wu, 2007). Active management of customer interactions can be attained by promoting the homogeneity of travelers, introducing a code of behavior, and preventing dysfunctional behavior (Wu, 2007). Throughout the tour, I witnessed the travel guide give an orientation, which included a code of behavior. Furthermore, the guide intervened and

prevented dysfunctional situations, such as travelers oversleeping during a departure day. Consequently, a practical implication from this study is the need for businesses engaged in hospitality and travel to target homogeneous groups of individuals in order to promote compatibility. Furthermore, service providers can intervene to prevent potentially uncivil or dysfunctional behaviors among customers. Given the various roommate challenges, travel companies that match single travelers can potentially give people a questionnaire in order to match people with similar interests and travel objectives.

The need to belong is a fundamental human motivation that guides voluntary and involuntary behaviors, thoughts, and emotions (Baumeister \& Leary, 1995). Furthermore, the 
frequency and stability of such connections is of outmost importance (Baumeister \& Leary, 1995). During the course of the tour, I noted how the influence of other travelers often enhanced the travel experience and created memorable events for participants beyond the destination itself. Given the importance of belonginess needs to the travel experience, travel operators can highlight the social aspects of such tours in their marketing campaigns. Rather than simply advertising destinations, routes, amenities, and other travel features; operators can market to individuals seeking a great social experience out of their travels. In spite of the many positive interactions that took place during the tour, several customer-to-customer factors served to inhibit the experience. Key among these was the heterogeneous nature of the group. Previous research suggests that service providers can actively manage the composition of their groups in an effort to improve the service experience: This is the core idea of compatibility management that was proposed by Martin and Pranter (1989).

Whereas prior research might have considered young travelers as one homogeneous travel segment, the present study shows otherwise. By utilizing an ethnographic approach, I was able to obtain rich information about travelers who participated in a 3-week long European journey. One of the research objectives proposed in the introduction was to gain a better understanding of consumer psychographics. Travelers differed in terms of their activities, interests, and opinions (AIO). The AIO framework, which is utilized by some marketers for the purposes of segmentation, has also been studied in academic circles, with the ultimate end of creating typologies of travelers (Galloway, 2002; Mehmetoglu, 2006). Some travelers were more active and adventurous, whereas others were less so. Some travelers had a great appreciation for arts and humanities, but the majority of travelers did not. Some were single, whereas others traveled with their significant others. 
Trip participants had different financial resources. Whereas some travelers tried to enjoy every activity and every meal regardless of the cost, others were more price-sensitive. It became evident that, with respect to travelers in their 20s and 30s, there were sharp contrasts between those who were still attending college and those who were young professionals. Given this situation, it's possible to target different tours to young travelers. Some tours can appeal to those with greater wallets by featuring more upscale hotels, and more tour inclusions. Other tours can provide the maximum value for the least amount of money. People also had different views on the extent of alcohol use during the length of the trip. It was also noted that the country of origin helped to form bonds of friendship among travelers, especially as they encountered new countries, languages, and cultures.

Travelers differed with regard to their levels of activity. Whereas some preferred to do every possible activity, others preferred to take a walk and soak up the scenes of the cities they visited. Some enjoyed shopping for items for themselves, as well as for souvenirs, whereas others decided early on that they would not be spending too much time and money in stores. Noting different levels of activity level even among the same age group can help tour operators better design the offering of excursions during the trip. The findings are especially relevant in light of the research on customer-to-customer interactions. Martin and Pranter (1989) coined the term "compatibility management," as they suggested that organizations should do a better job at matching up people with similar interests. Researchers, such as Vyncke (2002), stress the importance of such lifestyle segmentation strategies. This, in turn, would create a more pleasurable experience for the consumer. Given the findings of this research, I propose that tour companies appealing to the young travel market engage in additional efforts to segment their tour offerings based on psychographics. For example, the individuals who enjoyed drinking during 
the trip might be better served by a "nightlife tour of Europe," which would allow them to visit night-life spots and have a later start to their day. Those who preferred activities such as white water rafting could be better served by an "adventure tour" targeted toward the same segment. The young couples on the trip might be more satisfied by a "young couples' tour of Europe," where they would have opportunities to engage with other couples.

These are just a few examples of how tour operators could further segment the young travel market, find niches, and achieve better customer satisfaction through compatibility management. Given the large number of tours run by operators, it might be feasible to operate a few specialty tours based on travelers' AIO. Additionally, smaller entrepreneurial companies can look to this more targeted approach in order to create smaller tour groups with a very specific focus. I do not mean to discount the importance and utility of demographic segmentation; rather, I propose that travel companies can combine demographics and psychographics to create more targeted products and services, which will fill a market need and enhance satisfaction with the customer experience.

Another research objective proposed in the introduction was to study consumer decision making during the tour. Previous research suggested that the decision-making process is ongoing (Decrop and Snelders, 2005) and extends beyond the initial choice to travel, as subsequent decisions are made as the trip unfolds (Martin \& Woodside, 2012). Such decisions are sometimes referred to as "en-route purchase decisions" (Choi et al., 2012). During the tour, I observed participants make several decisions, including those pertinent to optional excursions, choice of restaurants, and purchase of merchandise. I propose that several factors influence these en-route decisions. Budgetary constraints are one reason why people make different choices. Whereas some travelers had more generous budgets for incidentals, others had relatively more limited 
resources. Time constraints also played a role in the choice of dining experience, as well as in the number of optional excursions taken. The tour guide helped to promote optional excursions; thus, he clearly had an influence on the choices made by tour participants. Different people had various goals during this trip, which, in turn, affected their purchases. Finally, but perhaps most important, I propose that en-route decisions not only be viewed as individual decisions, but also as collective ones, as they are heavily influenced by other group members. Consequently, some en-route decisions follow a pattern that is more consistent with group decision making, as opposed to the process used to make individualized choices. Given this reality, restaurants, retail shops, and operators of optional excursions can better market to this segment, conscious of the need to market to people as groups and seek out opinion leaders who are highly influential to such purchase decisions.

In previous research, scholars have examined the role of the tour guide (Curtin, 2010; Tsaur \& Wang, 2009; Wang et al., 2002). The present research adds to the body of knowledge by exploring the additional roles and behaviors of the guide. The trip's tour guide served as a combination of manager, social chair, salesperson, and, at times, parent figure. The actions of the guide, as well as the driver, during the tour made a significant impact on the enjoyment of the experience, as evidenced by the comments offered by tour participants. It was the tour guide's responsibility to make sure that everyone had a good time, to maintain a certain level of civility among the group, to provide suitable recommendations, to sell optional excursions and activities, and to ensure the safety and security of the travelers while navigating many countries presenting the challenges associated with different languages, currencies, and cultures. Despite the great importance of such personnel, training for tour guides tends to be informal, and their work conditions can be strenuous. These can lead to high levels of turnover, as our tour guide depicted 
existed in his company. Consequently, tour operators can make strides towards creating better conditions of employment for such critical group of individuals.

The present research contributes to the field by outlining the travel behaviors of people in their 20s and 30s. This research can help scholars to gain a better understanding of customer-tocustomer interactions, group dynamics, and decision-making processes as they occur in a natural setting. Practitioners can gain a better understanding of who their customers are, what they like, and how to better appeal to them in marketing campaigns. Furthermore, the present study proposes that tour companies can become more sophisticated in matching up travelers whose activities, interests, and opinions coincide. While the present research sheds light on this topic, it also has limitations. The key limitation is that information was gathered on only one European tour. While the tour lasted a considerable amount of time and featured 50 participants, more research can further investigate these topics in other similar tours. Although the demographic of the travelers in this tour is defined by the tour operator, and the participants were younger than those participating in other bus tours, age differences among travelers remained. The fact that the youngest participant was 18 , and the oldest was in the mid-30 range, can account for various differences. Nevertheless, even among those participants closest in age, meaningful differences in AIO were noted.

After the trip concluded, many travelers kept in touch through social media outlets. Many remain friends, although face-to-face contact is rare, owing mostly to the geographical dispersion of tour participants. The travel experience takes place in a physical location or series of locations; however, the event extends beyond the duration of the trip. Activities take place with specific people in defined locations. Such people, places, and services shape our overall perception of enjoyment. A moment in time subscribes each experience to history. However, the 
experience lives on: The memories we keep, recall, and cherish endure beyond the specific times and places we visit. The people with whom we enjoy them help to make those experiences particularly memorable and worthy of our desire to anxiously await the next adventure, journey, and pleasurable event, which is often a vacation.

\section{References}

Ap, J., \& Wong, K. (2001). Case study on tour guiding: professionalism, issues, and problems. Tourism Management, 22(5), 551-563.

Backwell, C., \& Mitchell, V. (2003). Generation Y female consumer decision-making styles. International Journal of Retail and Distribution Management, 31(2), 95-106.

Baumeister, R. F., \& Leary, M. R. (1995). The need to belong: Desire for interpersonal attachments as a fundamental human motivation. Psychological Bulletin, 117(3), 497529.

Bowen, D. (2002). Research through participant observation in tourism: A creative solution to the measurement of consumer satisfaction/dissatisfaction among tourists. Journal of Travel Research, 41(4), 4-14.

Bowen, D. (2008). Consumer thoughts, actions, and feelings from within the service experience. The Services Industries Journal, 28(10), 1515-1530.

Calvey, D. (2008). The art and politics of covert research: Doing 'situated ethics' in the field. Sociology, 42(5), 905-918.

Charmaz, K. (2004). Grounded theory. In S. N. Hesse-Biber \& P. Leavy (Eds.), Approaches to qualitative research (pp. 496-521). New York: Oxford University Press. 
Chathoth, P., Altinay, L., Harrington, R., Okumus, F., \& Chan, E. (2013). Co-production versus co-creation: A process based continuum in the hotel service context. International Journal of Hospitality Management, 32, 11-20.

Chernev, A. (2004). Goal-attribute compatibility in consumer choice. Journal of Consumer Psychology, 14(1/2), 141-150.

Chiang, L., Aikaterini, M., Tang, L, Shin, J., \& Morrison, A. (2014). A comparative study of generational preferences for trip-planning resources: A case of international tourists to Shanghai. Journal of Quality Assurance in Hospitality and Tourism, 15(1), 78-99.

Choi, S., Lehto, X., Morrison, A., \& Jang, S. (2012). Structure of travel planning process and information use patterns. Journal of Travel Research, 51(1), 26-40.

Christensen-Hughes, J. (1997). Sociological paradigms and the use of ethnography in hospitality research. Journal of Hospitality and Tourism Research, 21(1), 14-27.

Curtin, S. (2010). Managing the wildlife tourism experience: The importance of tour leaders. International Journal of Tourism Research 12, 219-236.

Curtin, S., \& Wilkes, K. (2005). British wildlife tourism operators: Current issues and typologies. Current Issues in Tourism, 8(6), 455-478.

Decrop, A., \& Snelders, D. (2005). A grounded typology of vacation decision-making. Tourism Management, 26(2), 121-132.

Duarte-Alonso, A., O’Neill, M., Lui, Y., O’Shea, M. (2013). Factors driving customer restaurant choice: An exploratory study from the Southeastern United States. Journal of Hospitality Marketing and Management, 22 (5), 547-567. 
Formica, S., \& Uysal, M. (2002). Segmentation of travelers based on environmental attitudes. Journal of Hospitality Marketing and Management, 9 (3/4), 35-49.

Galloway, G. (2002). Psychographic segmentation of park visitors markets: Evidence for the utility of sensation seeking. Tourism Management, 23(6), 581-596.

Gardiner, S., King, C., \& Grace, D. (2012). Travel decision making: An empirical examination of generational values, attitudes, and intentions. Journal of Travel Research 52(3), 310324.

Grove, S., \& Fisk, R. (1997). The impact of other customers on service experiences: A critical incident examination of 'getting along.' Journal of Retailing, 73(1), 63-85.

Guba, E., \& Lincoln, Y. (1982). Epistemological and methodological bases for naturalistic inquiry. Educational Communication and Technology, 30 (4), 233-252.

Haukeland, J. (1984). Sociocultural impacts of tourism in Scandinavia: Studies of three host countries. Tourism Management, 5(3), 207-214.

Hritz, N., Sidman, C., \& D’Abundo, M. (2014). Segmenting the college educated Generation Y health and wellness traveler. Journal of Travel and Tourism Marketing, 31(1), 132-145.

Huang, J., \& Hsu, C. (2010). The impact of customer-to-customer interaction on cruise experience and vacation satisfaction. Journal of Travel Research, 49(1), 79-92.

Janis, I. L. (1982). Groupthink. Boston: Houghton-Mifflin.

Johnson, G., \& Grier, S. (2013). Understanding the influence of cross-cultural consumer-toconsumer interaction on consumer service satisfaction. Journal of Business Research, 66(3), 306-313. 
Josiam, B., Hobson, J., Dietrich, U., \& Smeaton, G. (1998). An analysis of the sexual, alcohol, and drug related behavioral patterns of students on spring break. Tourism Management, $19(6), 501-513$.

Lugosi, P. (2006). Between overt and covert research: Concealment and disclosure in an ethnographic study of commercial hospitality. Qualitative Inquiry, 12(3), 541-561.

Lugosi, P. (2007). Consumer participation in commercial hospitality. International Journal of Culture, Tourism, and Hospitality Research, 1(3), 227-236.

Lugosi, P., \& Bray, J. (2008). Tour guiding, organizational culture and learning: Lessons from an entrepreneurial company. International Journal of Tourism Research, 10(5), 467-479.

Mansfeld, Y. (1992). From motivation to actual travel. Annals of Tourism Research, 19(3), 399419.

Martin, C. (1996). Customer-to-customer relationships: Satisfaction with the other customers' public behavior. Journal of Consumer Affairs, 30(1), 146-169.

Martin, C., \& Pranter, C. (1989). Compatibility management: customer-to-customer relationships in service environments. The Journal of Services Marketing, 3(3), 5-15.

Martin, D., \& Woodside, A. (2012). Structure and process modeling of seemingly unstructured leisure-travel decisions and behavior. International Journal of Contemporary Hospitality Management, 24(6), 855-872.

Mehmetoglu, M. (2006). Segmenting nature-based tourists based on travel mode choice. Journal of Hospitality Marketing and Management, 14(4), 47-67. 
Petrak, N. (2011). Generation Y: Soon to be your next best customers. Adventure Travel News. Retrieved May 15, 2014, from http://www.adventuretravelnews.com/generation-y-soonto-be-your-next-best-customers

Prebensen, N., \& Foss, L. (2010). Coping and co-creating in tourist experiences. International Journal of Tourism Research, 13(1), 57-67.

Prebense, N., \& Kleiven, J. (2006). Determined sun-seekers and others-travel motives, holiday type, and holiday behavior among Norwegian charter tours. Journal of Hospitality Marketing and Management, 14 (1), 75-97.

Quiroga, I. (1990). Characteristics of package tours in Europe. Annals of Tourism Research, $17(2), 185-207$.

Reisinger, Y., \& Steiner, C. (2006). Re-conceptualizing interpretation: The role of tour guides in authentic tourism. Current Issues in Tourism, 9(6), 481-498.

Saniford, P., \& Seymour, D. (2007). A discussion of qualitative data analysis in hospitality research with examples from an ethnography of English public houses. International Journal of Hospitality Management, 26(3), 724-742.

Seaton, A. (2002). Observing conducted tours: The ethnographic context in tourist research. Journal of Vacation Marketing, 8(4), 309-319.

Shils, E. (1982). Social inquiry and the autonomy of the individual. In M. Bulmer (Ed.), Social research ethics: An examination of the merits of covert participant observation (pp. 125141). London: Macmillan.

Tsaur, S., \& Wang, C. (2009). Tip-collection strategies, service guarantees, and consumer evaluations of group package tours. Journal of Travel Research, 47(4), 523-534. 
U.S. Travel Association. (2013). Travel facts and statistics. Retrieved May 14, 2014, from http://www.ustravel.org/news/press-kit/travel-facts-and-statistics

Veisten, K., Haukeland, J., Baardsen, S., Degnes-Odemark, H., \& Grue, B. (in press). Tourist segments for new facilities in national park areas: Profiling tourists in Norway based on psychographics and demographics. Journal of Hospitality Marketing and Management.

Vyncke, P. (2002). Lifestyle segmentation: From attitudes, interests and opinions, to values, aesthetic styles, life visions and media preferences. European Journal of Communication, $17(4), 445-463$.

Wang, K.-C., Hsieh, A.-T., \& Chen, W.-U. (2002). Is the tour leader an effective endorser for group package tour brochures? Tourism Management, 23(5), 489-498.

Wikström, S. (1996). The customer as co-producer. European Journal of Marketing, 30(4), 619.

Wu, C. (2007). The impact of customer-to-customer interaction and customer homogeneity on customer satisfaction in tourism service-The service encounter perspective. Tourism Management, 28(6), 1518-1528. 